\title{
CAMBIO TECNOLÓGICO Y NUEVA SOCIEDAD DE LA \\ INFORMACIÓN (CIBERSOCIEDAD).
}

\section{TECHNOLOGICAL CHANGE AND NEW INFORMATION SOCIETY (CYBERSOCIETY).}

\begin{abstract}
AUTORES
Luis Joyanes Aguilar: Universidad Pontificia de Salamanca. Licenciado y Doctorado en Ciencias Físicas, Doctor en Informática y Doctor en Sociología.

luis.joyanes@aol.com
\end{abstract}

\section{CURRÍCULUM VITAE}

Universidad Pontificia de Salamanca. Licenciado y Doctorado en Ciencias Físicas, Doctor en Informática y Doctor en Sociología.

\section{RESUMEN}

Lo que caracteriza a las nuevas tecnologías es su interdependencia, el hecho de que constituyan un sistema, en el que los avances de cada campo facilitan el progreso en otras áreas de innovación tecnológica en base sobre todo a la comunicabilidad de la información obtenida y a su traducción en el código específico de cada campo por medio de ordenadores telecomunicados entre sí. Es decir, los avances tecnológicos se apoyan en la comunicación de la información obtenida. Esta información facilita la interdependencia de las nuevas tecnologías. Por esta razón es crucial conocer cómo ha evolucionado la información en el tiempo, de modo que un estudio comparado nos ayude a descubrir de qué modo se ha ido produciendo el impacto social de las sucesivas tecnologías y cómo se han aprovechado o defendido, en caso negativo, las diferentes culturas. 


\title{
PALABRAS CLAVE
}

Cambios - Tecnología - Información - Nueva sociedad

\begin{abstract}
What characterizes the new technologies is their interdependence, that constitute a system in which the progress of each field will facilitate progress in other areas of technological innovation based on all the communicability of the information obtained and its translation specific code in each field through telecommunicated computers together. That is, technological advances are based on the communication of information obtained. This information facilitates the interdependence of new technologies. It is therefore crucial to know how information has evolved over time, so that a comparative study helps us to discover how it has been producing the social impact of successive technologies and how they have used or advocated, if not, different cultures.
\end{abstract}

\section{KEY WORDS}

Changes - Technology - Information - New Company

\section{ÍNDICE}

Sexta parte: UN POCO DE HISTORIA

12. La información en el tiempo: Las diferentes culturas.

NOTAS 
El profesor Joaquín Bandera, director de la revista "Cuadernos de Realidades Sociales", del Instituto de Sociología Aplicada de Madrid, al tener conocimiento de la aparición de una revista totalmente ideada para su publicación en Internet, nos ofreció este interesante artículo que reproducimos y que, dado su análisis del cambio social asociado a las formas actuales de comunicación, puede ser de gran transcendencia para Vivat Academia.

La extensión de este texto, realmente titulado "Cambio tecnológico y nueva sociedad de la información", hicieron inviable su publicación en un sólo número de Vivat Academia, ya de por sí bastante sobrecargada, razón por la cual decidimos ofrecerlo a nuestros lectores en varias entregas.

Esta sexta y penúltima parte del trabajo de Luis Joyanes nos ofrece un ameno apunte histórico de la evolución de la tecnología de la información. Esencialmente, este capítulo va revisando los diferentes útiles usados por el hombre a fin de realizar cálculos y comunicarse, desde la remota Antigüedad hasta nuestros días, en la llamada era del ordenador personal.

\section{La información en el tiempo: las diferentes culturas}

Lo que caracteriza a las nuevas tecnologías es su interdependencia, el hecho de que constituyan un sistema, en el que los avances de cada campo facilitan el progreso en otras áreas de innovación tecnológica en base sobre todo a la comunicabilidad de la información obtenida y a su traducción en el código específico de cada campo por medio de ordenadores telecomunicados entre sí NOTA63. Es decir, los avances 
tecnológicos se apoyan en la comunicación de la información obtenida. Esta información facilita la interdependencia de las nuevas tecnologías. Por esta razón es crucial conocer cómo ha evolucionado la información en el tiempo, de modo que un estudio comparado nos ayude a descubrir de qué modo se ha ido produciendo el impacto social de las sucesivas tecnologías y cómo se han aprovechado o defendido, en caso negativo, las diferentes culturas.

Los ordenadores han venido a llenar una necesidad sentida por la humanidad desde siempre: la necesidad de información. El genero humano ha precisado siempre de un medio para organizar sus observaciones de una manera sistemática. Los datos, por sí mismos, carecen de utilidad, deben ser procesados o sintetizados de alguna manera antes de que se hagan significativos: Las sociedades primitivas no distinguían entre los términos dato e información, pero la distinción existía y el sentido de esta distinción simboliza el desarrollo de los sistemas de procesamiento de datos NOTA64.

Las sucesivas civilizaciones, desde las más antiguas a las más modernas, aunque no hayan dispuesto de ordenadores, siempre dispusieron de elementos de cálculo, que les permitían sacar conclusiones de sus observaciones. En otras palabras, necesitaban información y la adquirían observando su entorno, cosa que no es sino una forma simple de procesamiento de datos.

Las sociedades agrarias más antiguas, desde la egipcia a la maya, aprendieron a anotar hecho y sucesos, tales como cuándo salía y cuándo se ponía el sol, cuándo hacía frío o cuándo hacía calor, cuándo llegaba la época de las lluvias o cuándo llegaba la época de las nieves, etc. Estos datos elementales sólo tenían utilidad hasta que fueron sintetizados. El hombre aprendió a organizar la siembra y la recogida del grano en función de la aparición de los fenómenos naturales. Los egipcios 
relacionaron las inundaciones del Nilo con las fechas en las que se producían los solsticios de verano e invierno.

Estos ejemplos y muchos otros tratan de poner de manifiesto cómo ya, desde la antigüedad, el ser humano, a partir de unos datos aparentemente sin utilidad o sentido, era y ha sido capaz de correlacionarlos entre sí, para generar una información que le fuera útil según sus necesidades. Sin embargo, no se podía hacer mucho, si no se disponía de tecnología y a su vez de máquinas adecuadas para su uso. Así, siguiendo la clasificación de Philipe Breton NOTA65, podemos considerar tres épocas en la historia del cálculo:

Primera época: Del ábaco a las máquinas de oficina.

Segunda época: La era de los ordenadores.

Tercera época: La era del cálculo artificial.

Primera época

La mayoría de las civilizaciones ha utilizado el lenguaje de la mano, como primer elemento de cálculo. Este método no se reducía simplemente a "contar con los dedos", sino que, al contrario, animaba a utilizar toda la riqueza física de la mano NOTA66. Existían numerosas técnicas en las diferentes culturas orientales, incas, aztecas, etc. Por ejemplo, en la civilización oriental, las personas negociaban transacciones comerciales, y fijaban sus precios, tocándose simplemente las manos, preferentemente bajo la ropa, para que la venta se hiciera aparte de las miradas del público presente. Otro sistema se basaba en sistemas artesanales; por ejemplo, los incas utilizaban, para los inventarios, una serie de cuerdecillas anudadas, con un código similar a éste: tres nudos, que servían para unir un manojo de cinco cuerdecillas, significarían 30.000, tres nudos que unieran dos cuerdecillas, significarían 30, tres nudos en una única cuerdecilla, la cifra sería 3. 
Pero es, seguramente, el ábaco, el mecanismo de cálculo más utilizado y eficiente desde la Antigüedad, ya que incluso hoy se utiliza todavía en algunos países orientales, o en juegos infantiles. Es un instrumento de cálculo que permite realizar operaciones aritméticas deslizando manualmente cuentas (piedras, anillos, conchas...) sobre varillas. Se puede considerar como la más antigua de las calculadoras digitales.

En 1945 NOTA67 se organizó un concurso en Japón, que enfrentó al soldado Thomas Nathan Wood, de la Armada de los Estados Unidos, y Kiyoshi Matsuzuki, empleado de la Caja de Ahorros. Wood había sido seleccionado entre los mejores calculadores de la Armada y disponía de una calculadora eléctrica de oficina, el empleado japonés trabajaba con ábaco (un marcador de bolas). El concurso consistía en realizar cinco tipo de cálculos que implicaban las cuatro operaciones. Desde el punto de vista de la velocidad y exactitud, el japonés consiguió cuatro de las pruebas y el soldado americano una.

La historia del cálculo, después del ábaco, continuó con las primeras calculadoras y pasó sucesivamente por las máquinas de Babbage y las primeras máquinas de oficina y de cálculo científico, esencialmente máquinas analógicas. Algunas fechas trascendentales en la historia de la información en esta primera época son las siguientes NOTA68:

4.000 a. de C.: Los sumerios idean el sistema sexagesimal de numeración.

3.000 a. de C.: Los egipcios agrupan números por decenas y los representan mediante jeroglíficos.

2.000 a. de C.: Los babilonios introducen el sistema decimal no posicional. 
300 a. de C.: Los matemáticos de Alejandría crean un sistema de numeración llamado alejandrino, basado en las letras del alfabeto (24 letras).

850: Los árabes adoptan el sistema decimal posicional que los hindúes habían desarrollado en el siglo II.

1550-1617: John Napier, inventor de los logaritmos, creó una máquina de multiplicar y las primeras calculadoras mecánicas.

1653: Blas Pascal creó la calculadora llamada pascalina. Era una máquina construida con ruedas dentadas y que permitía sumar y restar.

1671: El filósofo y matemático alemán Gottfried Leibniz construye la primera calculadora capaz de realizar las cuatro operaciones (en la pascalina, la multiplicación se hacía repitiendo la suma).

1864: Charles Babbage publica en Inglaterra los planos de la máquina analítica (analytical engine). Es considerada como el primer antecedente de la ordenadora y su inventor es reconocido como el primer padre de los ordenadores.

1889: Herman Hollerith inventa la tarjeta perforada y comienza a crear máquinas que procesan la información.

1896: Hollerith funda la empresa Tabulating Machine Corporation, que en 1924 se convirtió en IBM. 
1915: El español Leonardo Torres Quevedo construye el primer autómata capaz de tomar decisiones: una máquina jugadora de ajedrez.

1936: El matemático Alan Turing publica una tesis doctoral donde esboza la analogía entre datos e instrucciones, fundamento del concepto de programa almacenado, base de los ordenadores modernos.

Segunda época

La Informática, tal y como se entiende en la actualidad, suele considerar como fecha mágica de partida, o su "Big Bang" particular, el año 1946, con la construcción del gigantesco (por tamaño) ordenador ENIAC, construido por Eckert Y Mauchly apoyándose, fundamentalmente, en los trabajos teóricos y experimentales de von Neumann, que diseñó una arquitectura para ordenadores, que hoy prácticamente siguen todos los fabricantes de ordenadores. Fechas clave en esta segunda época son NOTA69:

1946: Creación del ordenador ENIAC, por los norteamericanos John W. Mauchly y Prosper Ecker. Pesaba 30 toneladas y medía 24 metros.

1947: Se inventa el transistor -dispositivo electrónico clave para el desarrollo tecnológico de la segunda mitad del siglo XX- en los laboratorios Bell de Estados Unidos.

1956: El periódico japonés Asahi Shimbun utiliza por primera vez la transmisión por fax a larga distancia. La empresa estadounidense Ampex inventa la grabadora de vídeo que graba magnéticamente una señal de televisión en una cinta de vídeo. 
1958: Se inventa el láser, el módem y el chip (circuito integrado). Estos dispositivos son elementos fundamentales en las tecnologías de la información.

1960: Se crea la empresa Digital Computer que a su vez construye el primer microordenador de la historia: el PDP 101.

1969: El Departamento norteamericano de Defensa pone en servicio una red militar de comunicaciones, denominada Arpanet, precursora de la actual Internet.

1970: Se crea el microchip, que contiene un microprocesador (la Unidad Central de Proceso de un ordenador).

1973: Se inventa el disquete o disco flexible (floppy disk).

1977: Steve Jobs y Stephen Wozniak construyen el Apple II, el primer microordenador comercial de la historia, basado en microprocesadores.

1978: Al Gore, vicepresidente de los Estados Unidos en 1996, acuña el término "superautopistas de la información".

1979: Comienza a funcionar el primer servicio de información interactivo que ofrece correo electrónico y bases de datos a disposición de los usuarios.

1980: Ted Turner crea la CNN, cadena de noticias por cable.

Tercera época: el ordenador personal 
Microsoft crea en 1981 el sistema operativo MS-DOS, que hoy llevan la inmensa mayoría de los ordenadores personales de cualquier marca y potencia.

IBM lanza en el año 1981 el PC (Personal Computer), primer ordenador personal, realmente profesional de la historia, y que, ha supuesto, posiblemente, uno de los mayores inventos de la humanidad, comparable a los inventos de la rueda o de la máquina de vapor. La fecha, 1981, se puede considerar el punto de partida de la tercera época de la sociedad de la información y es, seguramente, la fecha de comienzo de la revolución informática en que nos encontramos. Esta época es la que Philipe Breton denominó la época de cálculo artificial y que ya es conocida como la época cibernética. Las fechas clave de esta época son NOTA70:

1982: La casas Philips y Sony definen las normas para fabricar discos compactos musicales (CD, compact disk).

1983: AT\&T lanza el primer servicio comercial de teléfonos celulares (móviles).

1984: Lanzamiento del CD-ROM (memoria de sólo lectura en disco compacto). El CD-ROM tenía una capacidad de 540 millones de caracteres (equivalente a 250.000 páginas de texto). La firma japonesa Nintendo lanza el primer ordenador personal exclusivamente de juegos.

1985: Microsoft comienza a lanzar un entorno de sistema operativo bautizado como Windows y que hoy soportan la mayoría de los PC fabricados en el mundo.

1992: Europa implanta la primera norma mundial de telefonía móvil, llamada GMS.

1993: Apple lanza un ordenador personal que combina un ordenador, una televisión y un CD-ROM con tarjeta de sonido y que comienza a ser el boom de la multimedia. 
1994: Internet comienza a popularizar el sistema de comunicaciones interactivo más grande del mundo.

1995: Microsoft lanza en Septiembre la última versión de su sistema operativo al que denomina Windows 95 y que facilitará el acceso a las autopistas de la información, de un modo sencillo para cualquier usuario de un PC, y que puede ser el punto de partida real de la nueva era cibernauta.

1996: Se lanza el ordenador de red NC que pretende sustituir a los PC en todas las aplicaciones relacionadas con el mundo de las autopistas de la información e Internet (Este ordenador está apoyado por las multinacionales IBM, Sun, Oracle, etc.). Se lanza también, a finales de año el NetPC un ordenador portátil de tamaño miniatura -como las actuales calculadoras matemáticas o similar- con características similares a un PC y apoyado fundamentalmente por las multinacionales Microsoft, HP, etc.

CONTINUARÁ...

En el próximo número:

\section{LA REVOLUCIÓN SILENCIOSA Y LA CIBERSOCIEDAD}

NOTAS 
NOTA 63: MANUEL CASTELLS, Nuevas tecnologías, economía y sociedad en España, Madrid, Alianza Editorial, 1986, págs. 262-264.

NOTA 64: SEBASTIÁN DORMIDO, JULIÁN MORALES Y LUIS VICENTE ABAD, Sociedad y nuevas tecnologías, Madrid, Trotta, 1990, pág. 118.

NOTA 65: PHILIPE BRETON, op. cit., pág. 59.

NOTA 66: El lenguaje de la mano, UPSA, Salamanca, 1992. Lección inaugural del curso 1992/93 en la Universidad Pontifica de Salamanca en la sede de Salamanca.

NOTA 67: Ibíd., pág. 62.

NOTA 68: Existen numerosos historiadores de la ciencia informática. Queremos destacar más que como historiador, como conocedor y experto en Informática, a Luis Arroyo, que en su obra "200 años de informática", Espasa Calpe, 1991, págs. 253-295, incluye una excelente cronología de Informática que abarca el período de la historia: año 850 a 1991

NOTA 69: Suplemento "WorldMedia" de El País, 9 de Marzo de 1995, págs. 24-25.

NOTA 70: Ibíd., págs. 24-25. 